IdeAs

Idées d'Amériques

15 | 2020

Eau et gestion de l'eau dans les Amériques

\title{
Violaciones a los Derechos Humanos en largo octubre chileno
}

\section{Carolina Aguilera}

\section{(2) OpenEdition}

1 Journals

Edición electrónica

URL: https://journals.openedition.org/ideas/8386

DOI: 10.4000/ideas.8386

ISSN: 1950-5701

Editor

Institut des Amériques

Referencia electrónica

Carolina Aguilera, «Violaciones a los Derechos Humanos en largo octubre chileno », IdeAs [En línea],

15 | 2020, Publicado el 01 marzo 2020, consultado el 21 septiembre 2021. URL: http://

journals.openedition.org/ideas/8386 ; DOI: https://doi.org/10.4000/ideas.8386

Este documento fue generado automáticamente el 21 septiembre 2021

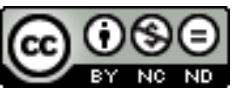

IdeAs - Idées d'Amériques est mis à disposition selon les termes de la licence Creative Commons Attribution - Pas d'Utilisation Commerciale - Pas de Modification 4.0 International. 


\title{
Violaciones a los Derechos Humanos en largo octubre chileno
}

\author{
Carolina Aguilera
}

Este texto se ha alimentado de conversaciones con colegas con los que hemos compartido la angustia por la represión vivida en el país, en especial Daniela Jara, Loreto López, Lucía Dammert, Alejandra Luneke, Manuela Badillfa, Paulo Álvarez y Fabián Flores, entre otros. En especial fue muy enriquecedor el seminario organizado el 27 de noviembre "DDHH en el Chile postdictatorial: La deuda pendiente" en el Museo de la Memoria y los DDHH, el cual contó con el apoyo de COES. Este artículo contó con el apoyo del Centro de Estudios de Conflicto y Cohesión Social COES CONICYT/FONDAP/15130009.

1 Enero de 2020. Han pasado tres meses desde que comenzó un inédito proceso de movilización social en el país, el que se ha transformado en el movimiento de protesta más masivo desde el fin de la dictadura de 1973-1990. Junto con la fuerza del movimiento, uno de los aspectos más llamativos han sido las reiteradas violaciones a los derechos humanos, las que continúan hasta el día de hoy, aun cuando haya querellas por personas asesinadas y por el homicidio frustrado por parte agentes del Estado (INDH, 2019), y denuncias por los atropellos desde organismos locales e internacionales.

2 Dicho panorama podría resultar inverosímil a primera vista, en un país que supuestamente contó con una transición pacífica -admirada en el mundo - para terminar con una dictadura sangrienta. ¿Qué pasó? En particular, ¿qué pasó con las garantías de no repetición que debieran formar parte la justicia transicional (RohtArriaza N., 2019)? Quisiera proponer como hipótesis que ello obedece a la incompletitud del proceso de Justicia Transicional expresado en dos dimensiones: la existencia de enclaves autoritarios heredados de la dictadura y la perduración de un discurso social dominante que justifica el abuso policial y el uso excesivo de la fuerza contra un "otro" considerado amenaza del orden social. 


\section{Violaciones a los DDHH desde el 18 de octubre de 2019 en Chile}

3 Los pactos internacionales en materia de DDHH, firmados y ratificados en el país consagran la obligación del Estado de resguardar el derecho a la vida y a no utilizar la tortura como procedimiento policial. Más aún, el propio protocolo de Carabineros declara el apego a esta normativa internacional para reglar el uso de la fuerza policial (Carabineros de Chile, 2019). Sin embargo, como han indicado los informes del Instituto de Derechos Humanos (INDH, órgano del Estado), la Comisión Interamericana de Derechos Humanos (CIDH), el Alto Comisionados de los DDHH de las Naciones Unidas, Human Rights Watch y Amnistía Internacional, no se han cumplido estos protocolos ni respetado los DDHH de los manifestantes (en su gran mayoría pacíficos).

4 En cifras, las que lamentablemente invisibilizan las dramáticas historias personales y familiares, al 30 de noviembre la justicia chilena (a través de la Fiscalía Nacional) tenía abiertas 23 investigaciones por muertes ocurridas durante el periodo de estado de emergencia, entre las que se encuentran 2 personas que murieron mientras estaban bajo el cuidado del Estado y 5 por acción de agentes del Estado (INDH, 2019). Esto, en un contexto en el cual a esa misma fecha más de 3000 personas han llegado a los hospitales y centros de salud con heridas, entre ellas 200 niños o adolescentes. En casi 2000 casos se trata de lesiones producidas por armas de fuego, y además se reporten lesionados por bombas lacrimógenas, entre otros. De las lesiones que más han impactado a la opinión pública chilena e internacional han sido la gran cantidad de lesiones oculares ${ }^{1}$. El INDH reportó al 30 de noviembre un total de " 347 heridas oculares, entre las que se cuentan estallidos del globo ocular, pérdidas de visión por trauma ocular irreversible y traumas oculares" (INDH, 2019: 35). Incluso dos personas han quedado completamente ciegas. Como declaró este organismo frente a la Comisión Interamericana de DDHH, el 11 de noviembre, en Chile se ha violado también el derecho a la manifestación pacífica (INDH, 2019)

5 El impacto de esta situación ha sido enorme en el país. Las redes sociales como Facebook, Twitter e Instagram, están inundadas de testimonios que grafican estos hechos de violencia. Pero así también ha podido ser observado por las encuestas de opinión pública. Por ejemplo, el Termómetro Social ${ }^{2}$ publicado el 15 de diciembre, reportaba que 3 de cada 4 chilenos considera que se violan sistemáticamente los DDHH en el contexto de la movilización social del país. Más aún, casi el total de la población rechaza el uso de los instrumentos -balines y los gases lacrimógenos- que han provocado las mutilaciones oculares y heridas de todo tipo a los manifestantes, de marchas pacíficas (Termómetro Social, 2019: 64)

6 ¿Cómo explicar esta verdadera crisis humanitaria, a pesar del fuerte rechazo que genera el actuar policial en la población?

\section{Enclaves autoritarios de la dictadura: violaciones a los DDHH y la autonomía de las policías}

7 Entre las medidas que consideró el Estado al inicio de la pos-dictadura para hacer frente a las violaciones a los DDHH del pasado, fue una reforma profunda a Carabineros que diera garantías de no repetición ${ }^{3}$. Sin embargo, ello no ha ocurrido en la 
profundidad requerida, a decir por las recomendaciones periódicas que ha realizado el Comité Contra la Tortura de las Naciones Unidas ${ }^{4}$ entre 1995 y 2018, y las recomendaciones del INDH desde que emite el Informe sobre la Función Policial por primera vez en 2011 (Aguilera C., et al. 2019). Como han dado cuenta estos informes, Carabineros siguió incurriendo en prácticas de uso excesivo de la fuerza y torturas, tanto contra manifestantes de protestas pacíficas como contra comunidades indígenas (especialmente Mapuche). Además, recientemente se han conocido montajes policiales realizados por Carabineros para inculpar mediante pruebas falsas a integrantes de comunidades indígenas y para ocultar su responsabilidad en asesinatos de este mismo grupo de personas (operación "Huracán" y asesinato de Camilo Catrillanca). Los Informes del INDH, las denuncias y los casos ante la CIDH dan cuenta de que no son casos nuevos. La relativa autonomía de esta institución de la tutela política ha quedado además reflejada, en el millonario fraude al fisco recientemente descubierto, y aun en investigación, que se eleva a la cifra de 28 mil 300 millones de pesos, involucrando a más cien personas 5 .

Dos razones, una más estructural y otra más política, permiten comprender esta situación. En primer lugar, Carabineros (y también las FFAA), y las violaciones a los DDHH se constituyeron en un enclave autoritario de la transición que aún no han podido desarticularse. Como argumentó Manuel Garretón (2009) una de las dificultades del proceso de democratización pos dictaduras y conflictos armados de los años 1970s y 1980s en la región latinoamericana, refería a la existencia de "elementos constitutivos de estos [regímenes autoritarios], que son heredados por el régimen post-autoritario, perdurando en éste y alterando la vida democrática y la expresión de la soberanía popular... y que limitan el carácter plenamente democrático de éste." (Garretón M. A., 2000: 124). Entre ellos están aquellos de tipo normativo-legal, como fueron el sistema binominal, los quorum calificados y las leyes orgánicas en Chile las que tienen rango constitucional (Garretón M. A., 2009) ${ }^{6}$. Una de estas leyes rige a Carabineros de Chile, lo que ha dificultado las reformas que se requerían hacer, y en particular le dan amplísimas atribuciones a la institución en la toma de decisiones y muy pocas posibilidades para que el poder político pueda interferir en ello (Dammert L., 2019b). Más aún, como argumenta Dammert (2019b) el Presidente de la República en la práctica no puede remover al General Director si no cuenta con el apoyo de éste.

Sin embargo, y en segundo lugar, como también ha argumentado la investigadora Dammert (2019a), ha habido falta de voluntad política para avanzar en reformas a las policías. Sintomático de ello fue la dificultad y demora en el traspaso de la dependencia institucional de Carabineros desde el Ministerio de Defensa al Ministerio del Interior, la que se logrará recién 20 años después de la recomendación del Informe Rettig (en 2011). Por el contrario, como muestran los estudios de la autora, las policías ${ }^{7}$ han logrado contar a lo largo de estos años (e independiente del signo político del gobierno) con un aumento sostenido de presupuesto y dotación de personal, sin que haya existido un mayor debate en torno a esta inversión, ni se tomen en cuenta estudios críticos a su labor (Dammert L., 2019a). La investigadora indica que ello obedecería al gran respaldo que ha tenido Carabineros en la opinión pública en el país, entre otros factores. Es de esperar que la deteriorada imagen actual de la institución permita finalmente avanzar en las reformas que se requieren. 


\section{Discursos sociales dominantes que justifican el abuso policial para eliminar a otros considerados indeseables en la sociedad}

10 Además de la existencia de enclaves autoritarios, a modo de hipótesis, quisiera proponer que las violaciones actuales a los DDHH de los manifestantes obedecen a la perdurabilidad de un discurso social dominante ${ }^{8}$ de larga duración, que justifica el abuso policial cuando se trata de personas identificadas como amenazas del orden social.

11 Este discurso se usó con fuerza como argumento justificatorio de las violaciones a los DDHH ocurridas en dictadura (Stern S., 2006; Lira E., 2009). Efectivamente, uno de los trabajos más detallados sobre la memoria colectiva sobre ese periodo mostró que hacia finales de los años 1990s aún pervivía de manera importante una narrativa sobre el pasado que defendía el Golpe Militar y los abusos de las Fuerzas Armadas y Carabineros como un costo social necesario para restituir el orden político y social que se habría quebrado durante el gobierno de la Unidad Popular (Stern S., 2006). El historiador lo llamó la memoria de la salvación. Si bien, estudios de opinión pública indicaban que este discurso se había ido tornado minoritario (Collins C., 2010), en el contexto actual hemos vuelto a escuchar que las policías requieren mayores atribuciones para poder controlar el orden público. De hecho en estos días [mediados de enero] está por aprobarse una ley que endurece las sanciones para quienes realicen barricadas o incurran en acciones disruptivas como forma de protesta.

12 Esta es una posición respaldada por amplios sectores de derecha en la opinión pública. En efecto, la encuesta de Termómetro Social da cuenta que para más de un $70 \%$ de quienes se identifican con la derecha, la violencia ejercida por FF.EE. y Carabineros hoy se explica por la necesidad de restablecer el orden público, detener hechos delictuales y en la autodefensa. Se trata de una posición compartida por el gobierno, quien ha respaldado el actuar de Carabineros.

13 Este actuar se condice con la forma en que el Estado ha llevado adelante su política, también, contra territorios en los que la política no ha logrado resolver el conflicto social como ha sido en la Araucanía y en aquellas poblaciones asediadas por el narcotráfico, desde 2001. Esta estrategia de militarización, ha sido duramente cuestionada por organismos de DDHH, afectando a comunidades del sur del país y poblaciones de la capital como La Legua, Santa Adriana, La Victoria y Lo Hermida (Luneke A., 2019). Como describe Luneke, se trata de una "presencia de fuerzas especiales ... constante por largos períodos, y [d]el cierre perimetral (forma militar de control territorial) ... aplicado sin ningún control externo y sin evidencia de resultados en la reducción del tráfico de drogas" o del conflicto (Luneke A., 2019: 1).

En estos casos es posible observar, al menos como hipótesis, la existencia de un discurso similar al que justificó las violaciones a los DDHH en dictadura, es decir, como un costo social necesario para reestablecer el orden social, y que en última instancia considera a los "otros", ya sea "terroristas" o "delincuentes", antisociales contra quienes se justifica la represión. 


\section{Reflexión final. Las deudas de las garantías de no repetición del proceso de Justicia Transicional chileno}

Las violaciones a los DDHH ocurridas en Chile durante este nuevo y masivo ciclo de protestas no forman parte de una excepcionalidad del proceso político chileno. Ya habían sido implementadas como parte de la policía contra población Mapuche, en territorios con alta presencia de narcotráfico y contra manifestantes. A pesar de las recomendaciones realizadas por el Comité contra la Tortura de las Naciones Unidas, órgano que venía advirtiendo la necesidad de implementar reformas para evitar el abuso policial desde 1995 a la fecha, y los reportes del INDH en la misma dirección, no se han llevado adelante reformas en Carabineros que hubieran implicado evitar la masividad de la represión actual. Por el contrario, el actuar de la institución y su impermeabilidad al poder político, han persistido como un enclave autoritario, soportado entre otros por un discurso social dominante que justifica cierto nivel de abuso policial como un costo necesario para reestablecer el orden público. En ese sentido, si bien las políticas de Justicia Transicional se pusieron como objetivo el Nunca Más, fallaron en promover una cultura de respeto a los DDHH en todos los sectores de la sociedad y en asegurar garantías de no repetición mediante una reforma profunda a Carabineros.

\section{BIBLIOGRAFÍA}

Aguilera, Carolina, et al., « Violaciones sistemáticas de los derechos humanos en el Chile democrático. Hacia un nuevo pacto social », El Mostrador, 12 de noviembre 2019, https://urlz.fr/ bAQT, consultado el 09/03/2020

Carabineros de Chile, « Protocolos para el mantenimiento del orden público », fecha? https:// urlz.fr/bAQS

Collins, Cath, « Opinión publica y derechos humanos en Chile », CHILE 2009: percepciones y actitudes sociales. Informe de la quinta encuesta nacional UDP. Universidad Diego Portales, p. 61-71, Junio de 2010, https://urlz.fr/bBjm, consultado el 09/03/2020

Dammert, Lucía (2019a), « La crisis de Carabineros: cuando no vemos lo evidente », Hilos tensados Para leer el octubre chileno, K. Araujo (ed.). Santiago de Chile. Editorial USACH, p.149-172

Dammert, Lucía (2019b), « Algunos problemas de la autonomía policial en Chile », Entrepiso, 19 de diciembre 2019, https://urlz.fr/bBjv, consultado el 09/03/2020

Garretón, Manuel Antonio, « Problemas heredados y nuevos problemas en la democracia chilena. ¿Hacia un nuevo ciclo? », Economía, Instituciones y Política en Chile. Gobierno de Chile, Ministerio Secretaría General de la Presidencia. Santiago, 2009, Serie Estudios, Volumen IV, p.101-111

Garretón, Manuel Antonio, La sociedad en que viviremos. Introducción sociológica al cambio de siglo, Santiago de Chile, LOM, 2000 
INDH - Instituto Nacional de DDHH. Informe Anual. Sobre la situación de los Derechos Humanos en Chile en el contexto de la crisis social. 17 de Octubre - 30 de noviembre 2019, Santiago de Chile, INDH, 2019

Lira, Elizabeth, «Las resistencias de la memoria. Olvidos jurídicos y memorias sociales », El Estado y la memoria, R. (ed.), Barcelona, RBA Libros, 2009, p.67-115

Luneke, Alejandra, « Militarización policial de "Plaza de la Dignidad”, una lógica que debe ser relegada », El Mostrador, 31 de diciembre de 2019, https://urlz.fr/bBj6, consultado el 09/03/2020

Martuccelli, Danilo, «El largo octubre chileno. Bitácora sociológica ». En Hilos tensados Para leer el octubre chileno, K. Araujo (ed.). Santiago de Chile. Editorial USACH: 369-476, 2019

Roht-Arriaza, Naomi, « Measures of Non-Repetition in Transitional Justice The Missing Link? », From Transitional to Transformative Justice, Paul Gready (ed.) Cambridge: Cambridge University Press: 105-130, 2019

Stern, Steve, Remembering Pinochet's Chile: On the Eve of London 1998: The Memory Box of Pinochet's Chile Bk. 1. Duke University Press, 2006.

Termómetro Social, Encuesta elaborada por el Núcleo Milenio en Desarrollo Social (DESOC) y el Centro de Microdatos, con el apoyo de la Universidad de Chile y su Facultad de Economía, y COES. 2da ola. Diciembre 2019, http://bit.ly/TermometroSocial2, consultado el 09/03/2020

\section{NOTAS}

1. Ver por ejemplo el reportaje "It's mutilation. The Police in Chile are Blinding Protesters" de Brent McDonald del New York Times [https://urlz.fr/bBlA].

2. Encuesta realizada por, y aplicada entre los días 28 de noviembre y jueves 12 de diciembre, con 1.215 encuestas completadas a una población objetivo de 18 años y más, "residentes en zonas urbanas de las regiones de Biobío, Valparaíso y Metropolitana" (Termómetro Social, 2019).

3. Esta fue una de las recomendaciones de la Comisión de Verdad y Reconciliación (conocida como Informe Rettig)

4. Los informes pueden ser descargados via este link minimizado [https://urlz.fr/bBm6]

5. [https://urlz.fr/bBka]

6. Según se explica en el sitio web institucional de la Biblioteca del Congreso Nacional de Chile: "Leyes orgánicas constitucionales [son] normas complementarias de la Constitución relativas a ciertas materias expresamente previstas en el texto constitucional. Son objeto de un control preventivo de constitucionalidad por el Tribunal Constitucional y no pueden ser materia de delegación de facultades legislativas. Para ser aprobadas, modificadas o derogadas, se requiere de cuatro séptimas partes de los Senadores y Diputados en ejercicio" (BCN, s/f [https://urlz.fr/ bBk6]).

7. Además de Carabineros, Chile cuenta con una Policía de Investigaciones.

8. Utilizo este concepto de Alain Touraine según ha sido utlizado por Martuccelli (2019) 


\section{AUTOR}

\section{CAROLINA AGUILERA}

Carolina Aguilera : COES / IEUT-Universidad Católica de Chile caaguilera@uc.cl 